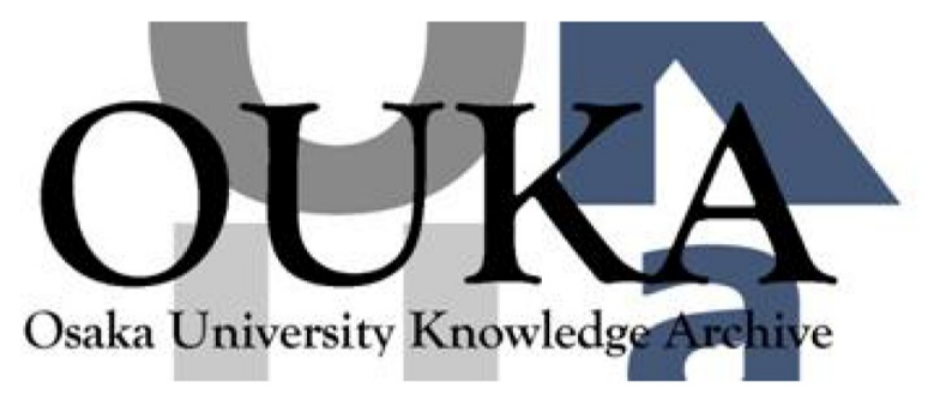

\begin{tabular}{|c|l|}
\hline Title & $\begin{array}{l}\text { Microcracks, spall and fracture in glass : A } \\
\text { study using short pulsed laser shock waves }\end{array}$ \\
\hline Author(s) & Li, Xin-Zen; Nakano, M. ; Yamauchi, Y. et al. \\
\hline Citation & Journal of Applied Physics. 83(7) p. 3583-p. 3594 \\
\hline Issue Date & $1998-04-01$ \\
\hline oaire:version & VoR \\
\hline URL & https://hdl. handle.net/11094/3025 \\
\hline rights & \\
\hline Note & \\
\hline
\end{tabular}

Osaka University Knowledge Archive : OUKA

https://ir. Library. osaka-u. ac. jp/

Osaka University 


\title{
Microcracks, spall and fracture in glass: A study using short pulsed laser shock waves
}

\author{
Xin-Zen Li, ${ }^{\text {a) }}$ M. Nakano, Y. Yamauchi, and K. Kishida \\ Department of Precision Science and Technology, Osaka University, 2-1 Yamada-oka, Suita, \\ Osaka 565, Japan \\ K. A. Tanaka \\ Department of Electromagnetic Energy Engineering and Institute of Laser Engineering, Osaka University, \\ 2-6 Yamada-oka, Suita, Osaka 565, Japan
}

(Received 6 May 1996; accepted for publication 5 January 1998)

\begin{abstract}
This work reports our meso mechanical study of microcrack behavior, especially the process leading from microcracking to macro failure. Using laser loading with a duration on the order of nanoseconds, spallation in a cylindrical geometry was achieved in soda-lime glass at the microcrack evolution stage. Laser induced shock waves were used to conduct crack initiation experiments for the first time. The specimens were examined after experiments and were compared with those loaded by conventional static and dynamic methods. A meso scale failure model of nucleation, growth, and percolation (NGP) is suggested based on the experiments. The NGP model is characterized by a randomly generated microcrack field and by simultaneous percolation statistics in time iteration. In most existing damage models, the statistical average of microcracks over a finite space is required in order to evaluate the damage variables. This procedure is not necessary in the NGP model. We show that the connection of microcracks can be very complicated, possibly a self-organized process. (C) 1998 American Institute of Physics. [S0021-8979(98)05407-3]
\end{abstract}

\section{INTRODUCTION}

We refer a brittle fracture to the spallation or unstable crack initiation in brittle materials here. The two phenomena are usually interpreted differently.

For spallation under short pulsed loading, the failure due to uniaxial strain load is usually studied. Most of the current models use the macro description method. The one established by Tuler and Butcher is well known. ${ }^{1}$ Some other recent works were performed by Kanel et al. ${ }^{2}$ and Resseguier et $a l^{3}$ In Resseguier's model the damage quantity was assumed to be the volume percentage of voids. The fracture criterion was considered to be the point when the void percentage exceeded $20 \%-25 \%$. The concept of void percentage is reasonably applicable to ductile materials, but it is difficult to imagine a $20 \%$ void percentage in a brittle material such as glass. Obviously, these models should be improved with respect to the following aspects: (1) the term usually used to express the damage variable does not accurately reflect its reality, (2) the growth of the damage follows an empirical equation, and (3) the failure limit of the damage is artificially designated.

On the other hand, elastic fracture mechanics are interpreted using the stress intensity factor (SIF) concept and the relationship between the surface energy release rate and critical SIF (fracture toughness). The sensitivity of fracture toughness to the loading rate is an important topic of

${ }^{a)}$ Present address: Computational Mechanics Technology Dept., Advanced Technology R. \& D. Center, Mitsubishi Electric Corporation, 1-1, Tsukaguchi-Honmachi 8-Chome, Amagasaki, Hyogo 661, Japan; Electronic mail: li@mec.crl.melco.co.jp study. ${ }^{4-6}$ This was empirically summarized as the "minimum incubation time criteria." 7 The criteria suggested that the time to failure was necessary for the evolution of microscopic damage. Here, a microcrack field in the process zone of a main crack serves to relax the stress level at the crack tip and enlarges the amount of area that supports the loading. The residual strength of the damaged zone is the key factor governing the main crack initiation.

A comprehensive description of both spall and crack initiation phenomena was given by the NAG model of Curran et $a l .{ }^{8}$ In the NAG model, the meso structures (e.g., voids or microcracks) were studied experimentally and numerically. The idea of the NAG model was widely accepted with different damage variable definitions. ${ }^{9}$ Traditionally, Boltzmann type statistics were used to define such damage variables. They were defined using a distribution function and then averaged according to the distribution. ${ }^{10}$ Such an average procedure eliminated the singularity of microcracks, and was fundamentally inappropriate for brittle fractures.

Curran et $\mathrm{al}^{8}{ }^{8}$ also suggested the advantages of using the short shock pulse technique. This technique freezes the damage in the evolutionary stages and connects it to a clear stress history. The short shock pulse is often obtained by the impact of a thin plate to a disk shape specimen.

A strong pulsed laser provides us with a new opportunity of obtaining shock waves short enough and yet strong enough for the task. ${ }^{11,12}$ Currently, laser induced shock waves are used to undertake material property studies in a very high pressure range $\left(10^{2}-10^{3}\right.$ times of the yield threshold) and spallation tests of very small specimens (less than 1 $\mathrm{mm}) .{ }^{13,14}$ We realized that this loading method also has the ability to carry out damage studies of the yield stress range 
TABLE I. Experimental scheme.

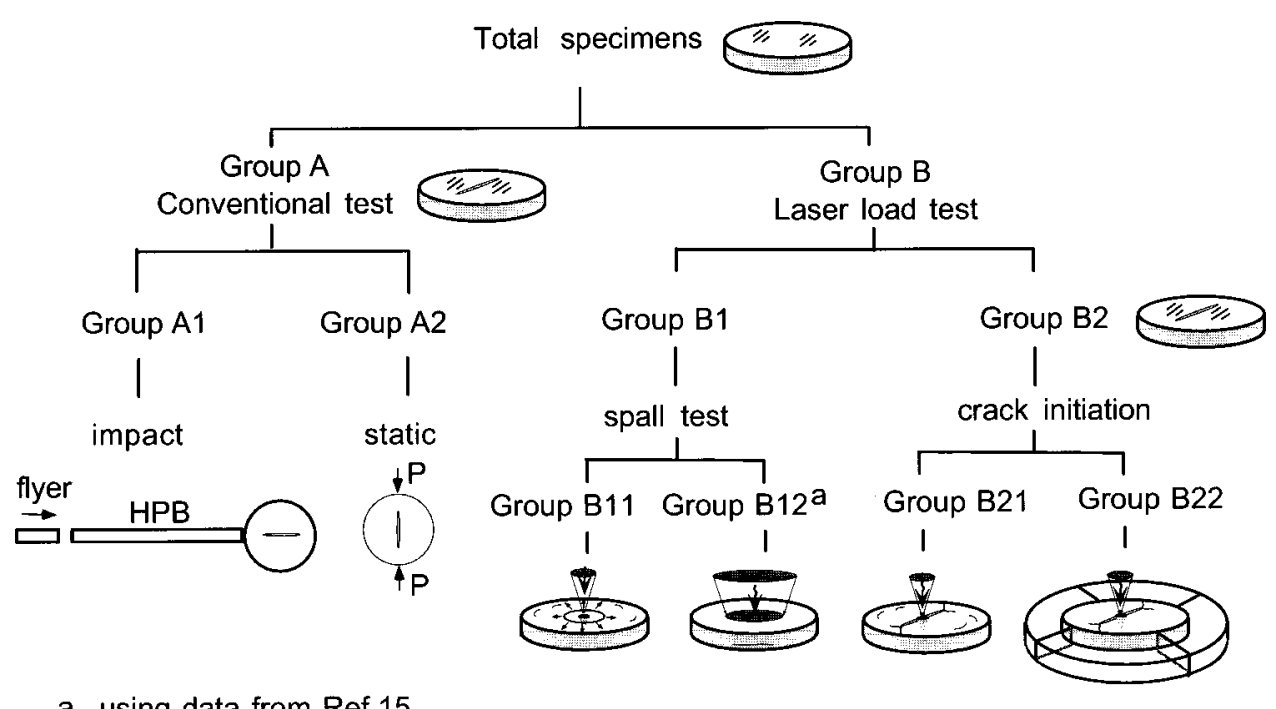

a. using data from Ref.15

as well. In this article, we describe a new plane strain experiment using a cylindrical geometry which is suitable for fracture experiments with specimens on the order of a centimeter. Because a successful fracture model should be efficient over a wide range of load duration and specimen geometry, we not only simulated our own experiments, but also simulated experimental data from spallation in plate specimens taken from Resseguir, ${ }^{3}$ so as to consider all data comprehensively.

Commercial soda-lime plate glass (window glass) was chosen as the test material. Hugoniot data are available up to $40 \mathrm{GPa} .{ }^{15,16}$ Recently the failure properties of various glasses have received special attention. There are reports that the failure waves were observed in soda-lime glass. ${ }^{17,18}$ Laser shock wave spall tests using plate targets have also been reported. ${ }^{3,19}$ The fracture toughness in mixed mode static fracture experiments was studied by Singh et al. ${ }^{20}$ About three years ago, we also studied the fracture behavior under mixed mode and dynamic loading. ${ }^{21}$ The fracture toughness of glass showed a rate dependent behavior. We found that if a modification to the maximum hoop stress (MHS) was made taking into consideration the nonsingular terms in front of the crack tip of a center notched disk specimen, the MHS criterion could well predict the extension direction of the crack tip in mixed mode experiments. ${ }^{22}$

Percolation theory ${ }^{23,24}$ seems to be a promising tool in establishing new models although it is still too simple for our requirements. The theory is attractive because the percolation criteria are simple and elegant. Our fracture model is

TABLE II. Chemical components of soda-lime glass.

\begin{tabular}{lccllc}
\hline \hline & $\mathrm{SiO}_{2}$ & $\mathrm{NaO}$ & $\mathrm{CaO}$ & $\mathrm{MgO}$ & $\mathrm{CuO}$ \\
\hline This work & $71.6 \%$ & $13.3 \%$ & $9.8 \%$ & 4.3 & $\ldots$ \\
Resseguier et al. $^{\mathrm{a}}$ & $71.5 \%$ & $13.7 \%$ & $9.5 \%$ & $4.05 \%$ & $\ldots$ \\
Dremin et al. $^{\mathrm{b}}$ & $72.2 \%$ & $14.1 \%$ & 0.0 & $0.1 \%$ & $12.5 \%$ \\
\hline \hline
\end{tabular}

${ }^{a}$ See Ref. 15.

${ }^{\mathrm{b}}$ See Ref. 16. obtained by interpreting the accumulation stage of the NAG model using the percolation theory. By percolation we mean that the representative quantity of the damage field is represented by the largest damage cluster instead of the traditional average variables. Other similar approaches have also been reported recently. ${ }^{25,26}$ In this way, a natural macro fracture criterion is obtained if the largest cluster span extends to the specimen size. The sign of the fracture is indicated by the presence of scaling law in crack clusters.

In this work, we first confirmed the material properties of glass under conventional loading. Then the spallation and crack initiation experiments were conducted using a pulse laser as the load source. The results of different experiments were then compared by fracture surface observation. Nucleation, growth, and percolation (NGP) were distinguished as the three basic stages of the failure process. This idea was checked with respect to spall and crack initiation experiments using the same material parameters. It can be concluded that the NGP model reasonably reflected the main features of all the experiments. However, the interaction between stress and the microcrack field still remained a problem which limited the accuracy and efficiency of the simulations.

\section{CRACK INITIATION EXPERIMENTS LOADED BY STATIC, IMPACT, AND PULSED LASER}

Table I illustrates our experimental scheme. The total specimens are divided into two groups of conventional loading experiments in Group A, and laser loading experiments in Group B. Some of the experiments had been reported before, ${ }^{3,21}$ but it is the first time we conducted all the experiments simultaneously. We intended to collect the comprehensive data of glass by such an experimental scheme.

\section{A. Conventional mechanical properties of soda-lime glass}

First, we repeated the experiments reported by our group previously. ${ }^{21}$ This served to confirm the material constants in 


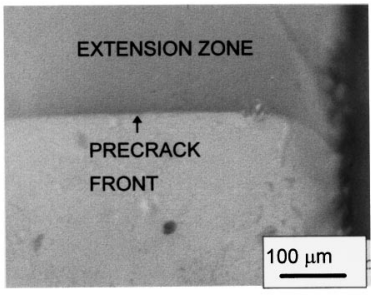

(a)

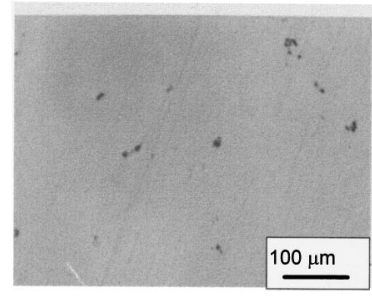

(b)
FIG. 1. The voids in soda-lime glass appeared as black spots in the pictures; (a) fracture surface (SP113) in static experiments; (b) section inside a glass specimen obtained by grinding.

soda-lime glass. The chemical components are listed in Table II and it can be seen that the glass we used was almost the same as that used by Resseguier et al. ${ }^{15}$ This time, glass disks $20 \mathrm{~mm}$ in diameter and $2 \mathrm{~mm}$ in thickness were used. For specimens which required existing cracks, two opposed arced slots were fabricated along the meridian on the faces of the disk by a diamond wheel with a thickness of $0.2 \mathrm{~mm}$. Thus a center chevron notch was formed. Then precracks were opened by applying pressure in the notch direction using an INSTRON. The precrack length was monitored by a charge coupled device (CCD) microscope camera with a 30 $\mu \mathrm{m}$ resolution. We use $R$ to indicate the specimen radius and $2 a$ to indicate the total crack length. The typical value of $a / R$ was 0.5 . The static tests were conducted with a loading head velocity of $0.1 \mathrm{~mm} / \mathrm{min}$. The time from the start to the end of loading was about $200 \mathrm{~s}$. The fracture toughness obtained was $0.7 \mathrm{MPa} \mathrm{m}^{1 / 2}$ when using the analytical solution. ${ }^{21}$ The static loading rate of the crack is on the order of $10^{-3} \mathrm{MPa} \mathrm{m}{ }^{1 / 2} / \mathrm{s}$. The impact loading fracture experiment was conducted on a Hopkinson pressure bar using the one point impact method. ${ }^{22}$ The fracture time was $6.7 \mu \mathrm{s}$, and the fracture toughness was $1.0 \mathrm{MPa} \mathrm{m}^{1 / 2}$, so the loading rate was around $10^{6} \mathrm{MPa} \mathrm{m}^{1 / 2} / \mathrm{s}$. Figures 1 (a) and 2(a) show typical fracture surfaces after the static and impact loading. Occasionally, there are slight hackles along the loading direction on the fracture surfaces which experienced impact loading. This can be regarded as an indication of a higher extension velocity. The fracture toughness results were the same as those obtained earlier. These material constants are summarized in Table III. We found that there were many voids ranging in size from 2 to $50 \mu \mathrm{m}$ on the fracture surfaces as seen in Figs. 1(a) and 2(a). We compared the surface obtained by grinding $1 \mathrm{~mm}$ into a cut surface and the result is shown in Fig. 1(b). The number and distributions of voids showed no obvious differences with that on the fracture surface. Figure 3 gives the results of the void distribution. In

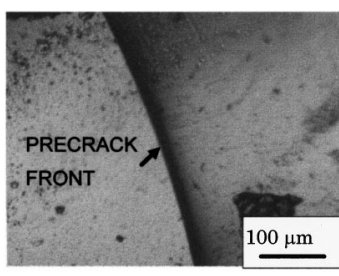

(a)

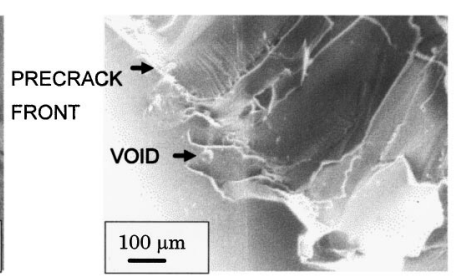

(b)
FIG. 2. Fracture surface in the striker impact and the laser loading experiments; (a) SP111 loaded by HPB one point impact, (b) SP007 loaded by laser shock waves. The arrows indicate voids that initiated cracks.

fact, the existence of these voids is well known by glass makers. ${ }^{27}$ They are formed during the chemical reaction in the later stages of glass formation.

There are two specific points to be noted regarding Figs. 1(a) and 2(a). One is that the precrack front can be clearly seen as a smooth line and it was not disturbed by the existing voids. The other is that a single crack front was preserved to the last stage of extension. We examined the surface shape and roughness of the fracture surface with a micro-surface meter with a $0.1 \mu \mathrm{m}$ spatial resolution and did not find any evidence of multi-fractures in both experiments of group A.

\section{B. Laser fracture experiments of plane strain cylindrical shock waves}

The specimens in the laser loading experiments were basically the same glass disks that were used in the conventional loading tests. A $1 \mathrm{~mm}$ diam center hole was opened as the laser absorption chamber for the laser load. Tungsten powder mixed with Araldite was used to form the cone shaped chamber shown in Fig. 4. A Nd-glass laser called the Gekko MII by the Institute of Laser Engineering (ILE) of Osaka University was used. The laser has a time duration of $0.5 \mathrm{~ns}$ and single shot energy up to $50 \mathrm{~J}$. The wavelength of the beam was $0.53 \mu \mathrm{m}$. In the experiments, the laser was focused to a $0.4 \mathrm{~mm}$ spot. The laser intensity was around $10^{12} \mathrm{~W} / \mathrm{cm}^{2}$. The pressure on the surface of the tungsten should be 20-100 GPa according to the scaling laws of Phipps et al. ${ }^{28}$ The duration of the pressure application should be the same as the laser plasma life which is less than $2 \mathrm{~ns}$ in our case. ${ }^{22}$ Since we are not able to measure the shock response of the self-made tungsten mixture, the pressure transmitted to the glass could not be calculated, but the pressure pulse must be longer in time and weaker in pressure than the plasma pressure. In this article, we supposed that the load to the glass had a pressure of $30 \mathrm{GPa}$ and a duration of $30 \mathrm{~ns}$.

TABLE III. Material parameters.

\begin{tabular}{lcclcl}
\hline \hline Specific volume & $v(\mathrm{cc} / \mathrm{g})$. & 0.3809 & Raleigh wave speed & $C_{R}(\mathrm{~km} / \mathrm{s})$ & 3.06 \\
Young's module & $E(\mathrm{GPa})$ & 71.3 & Static fracture toughness & $K_{1 c}\left(\mathrm{Mpa} \mathrm{m}^{1 / 2}\right)$ & 0.7 \\
Poisson's ratio & $\nu$ & 0.24 & Energy release rate & $J\left(\mathrm{~J} \mathrm{~m}^{-2}\right)$ & 7.3 \\
Longitude wave & $C_{L}(\mathrm{~km} / \mathrm{s})$ & 5.65 & Dynamic fracture & $K_{1 d}\left(\mathrm{MPa} \mathrm{m}^{1 / 2}\right)$ & 1.0 \\
Speed & & & & \\
\hline \hline
\end{tabular}




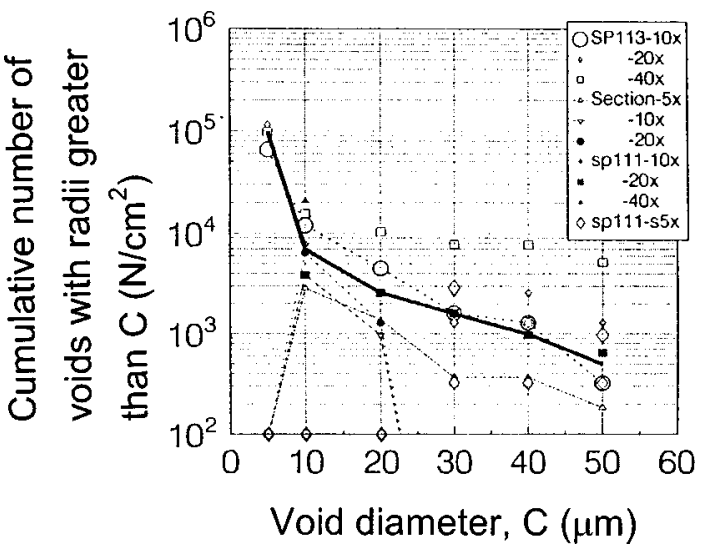

FIG. 3. Size and number distribution on the soda-lime glass sections. The samplings were taken from the specimens shown in Figs. 1 and 2. The broad line is the average for all the samples.

There were two groups of laser experiments B1 and B2. Group B1 was the spallation testing of cylindrical waves using specimens without a main crack. Under the supposed load, the compressive shock pulse generated in the center hole propagated radically and reflected as a tensile wave pulse when it reached the free edge of the disk. The shock front was relaxed during its propagation as its energy was dissipated, and the pulse span elongated as shown by Fig. 5 . The maximum shock wave pulse length was about $0.2 \mathrm{~mm}$. For a specimen thickness of $2 \mathrm{~mm}$, the loading inside most regions is strictly plane strain. This could be indirectly proved by observations after the shock experiments because the spallation cracks occurred in the middle of the specimen's height and usually did not reach the surfaces. One of the specimens was broken into small pieces. A microscopic observation of the pieces showed a lot of arc shaped cracks with distances less than $1 \mathrm{~mm}$ between the arcs; these arc shaped cracks took the laser incident hole as their center. This crack pattern was the same as with the other specimens. A possible problem for the method is the effect of secondary loading when the reflected tensile shock pulse is again reflected from the center. We examined the shock wave changes over a long time duration using computer simulation; the numerical simulation showed that the nonlinear constitutive zone, with pressure larger than $3 \mathrm{GPa}$, extended for about $0.2 \mathrm{~mm}$ from the center hole. The permanent deformation in the nonlinear zone worked to generate a very high tensile hoop stress when the shock pulse came back from the free edge. The shock amplitude transmitted to the outer region of the disk was below $1 / 10$ of the first shock pulse. The radial cracks formed around the center hole ex-
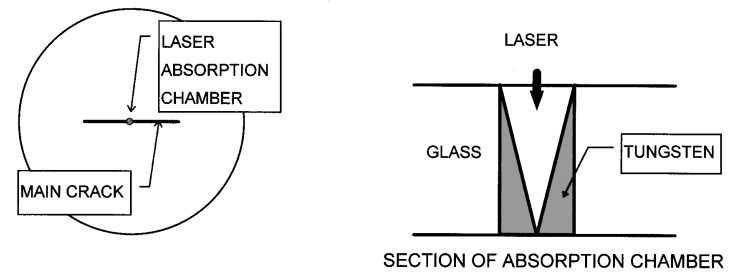

FIG. 4. Specimen shape and laser absorption chamber structure.
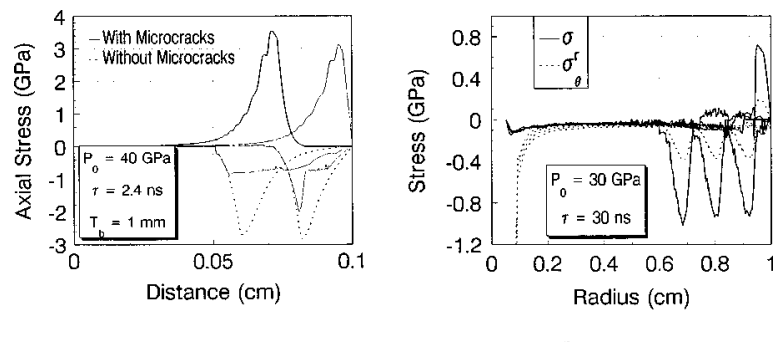

(a) $T_{b}$ is the target thickness

(b)

FIG. 5. Calculated stress profiles in uniaxial strain and plane strain cylindrical assumptions. The input load is rectangular shape with amplitude $P$ and duration $\tau$ indicated inside the figures, respectively: (a) uniaxial strain wave plotted every $40 \mathrm{~ns}$ from $0.12 \mu \mathrm{s}$. The calculation parameters were same as Ref. 3; (b) plain strain cylindrical shock wave plotted every $0.2 \mu \mathrm{s}$ from $1.6 \mu \mathrm{s}$.

tended for about $1 \mathrm{~mm}$, then the arc shaped cracks appeared as the main damage form. We are therefore sure that the regions $5 \mathrm{~mm}$ away from center of the specimen are almost free of secondary loading. Our observations and numerical simulations used the data obtained only in this region. Figure 6 shows an example of spall cracks before the final failure.

The B2 group specimens were used for the crack initiation tests. Each specimen in B2 had a center crack like those in the conventional loading experiments. We further designed two types of targets, B21 and B22, for those experiments. Group B21 had no lateral constraints. Figure 7 gives an example of the results of the overall damage. There was also spall damage in the lateral region of the main crack line. Figure 2(b) is a scanning electron microscope (SEM) microphotograph of the crack surface and shows a lot of microcracks on the precrack front. We found evidence that the microcracks were initiated from the preexisting voids as seen in Fig. 8. Group B22's targets used four $\pi / 2$ arc shaped glass buffers as momentum traps around the disk specimen. Figure

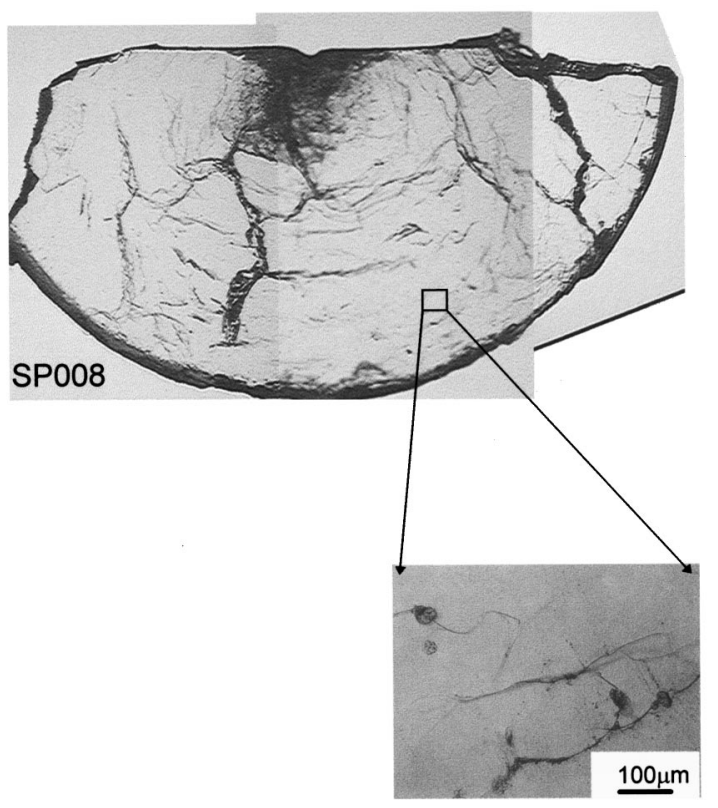

FIG. 6. Series observations with different amplification factors for spallation damage. The clusters of arc shaped cracks exist in different sizes. 


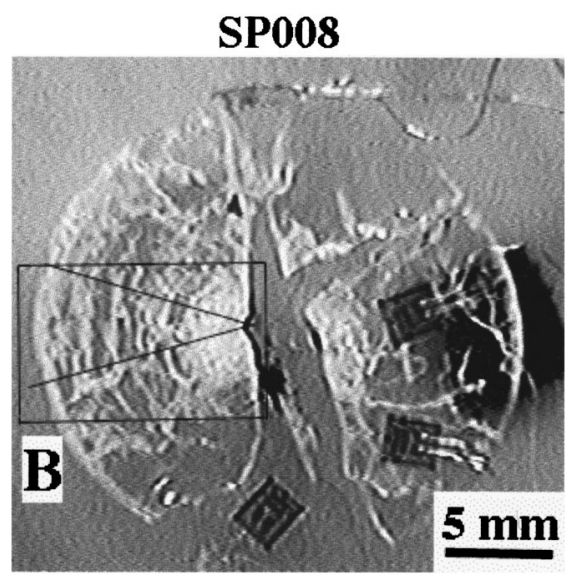

FIG. 7. An example of the fracture experiment specimen without buffers. The $\mathrm{B}$ section is dominated by the spallation damage.

9 illustrates targets of this kind. The spall cracks were eliminated in these specimens. Unlike the case of a uniaxial strain wave, only the $r$-direction momentum could be absorbed by the momentum traps. The $\theta$-direction momentum was still reflected. Under both kinds of group, B21 and B22, the crack extensions under the laser loading were characterized by crack bifurcation at the initiation points. The angle between the two branches was $110^{\circ}-140^{\circ}$. The crack branching that has been previously reported occurred during crack propagation, and the angle between branches was between $45^{\circ}$ and $90^{\circ}$ in most papers. ${ }^{29}$ The crack surfaces in the later stage, about $1 \mathrm{~mm}$ after initiation, was much smoother than the initial stage. The fracture process was recorded by a highspeed framing camera. ${ }^{22}$ Figure 10 is one example of the crack initiation characterized by branching at the beginning with the terminal velocity. The timing of the branch was within $2 \mu$ s from laser irradiation. The earliest reflection wave took $10 \mathrm{~mm}$ to the disk edge and $4 \mathrm{~mm}$ back to the new crack tip. This would take $2.4 \mu \mathrm{s}$. We concluded that the

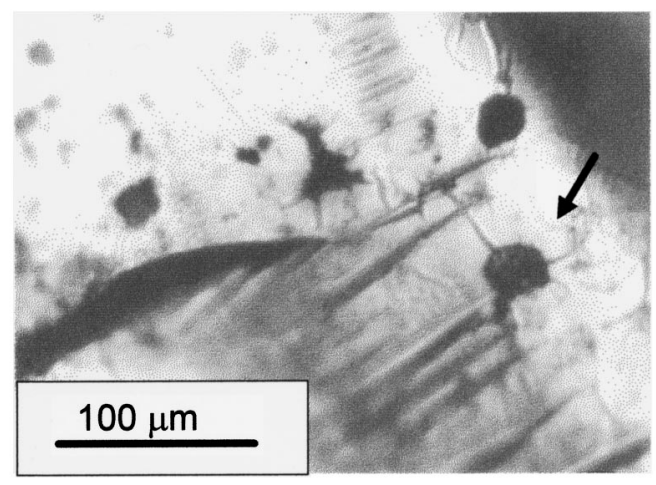

FIG. 8. Picture taken from fracture surface of the laser experiment. Cracks were generated from the voids as the location indicated by an arrow.

main crack was initiated by the first loading. The details of our later works have been reported elsewhere. ${ }^{30} \mathrm{We}$ did not attempt to evaluate the fracture toughness or the loading rate for the laser experiments.

\section{NGP MODEL FOR SODA-LIME GLASS}

Soda-lime glass is understood to have an "open ring", structure. The "ring" is composed of $-\mathrm{SiO}_{4}$-ion tetrahedrons. Two $\mathrm{Na}^{+}$ions are located in the space between two “open"-Si-O-branches. Soda-lime glass lacks the structural possibility of plasticity. However, the ring size-that is the number of silicon ions in one ring — can be changed. We regard this as so called densification. Our point of view is stimulated by the recent works of West et al. ${ }^{31,32}$ There is also experimental data that the densification starts from the pressure of $3 \mathrm{GPa}$. This is the Hugoniot elastic limit $\sigma_{\mathrm{HEL}}$, and is completed at $17 \mathrm{GPa}$. Using shock relationship for the flow stress
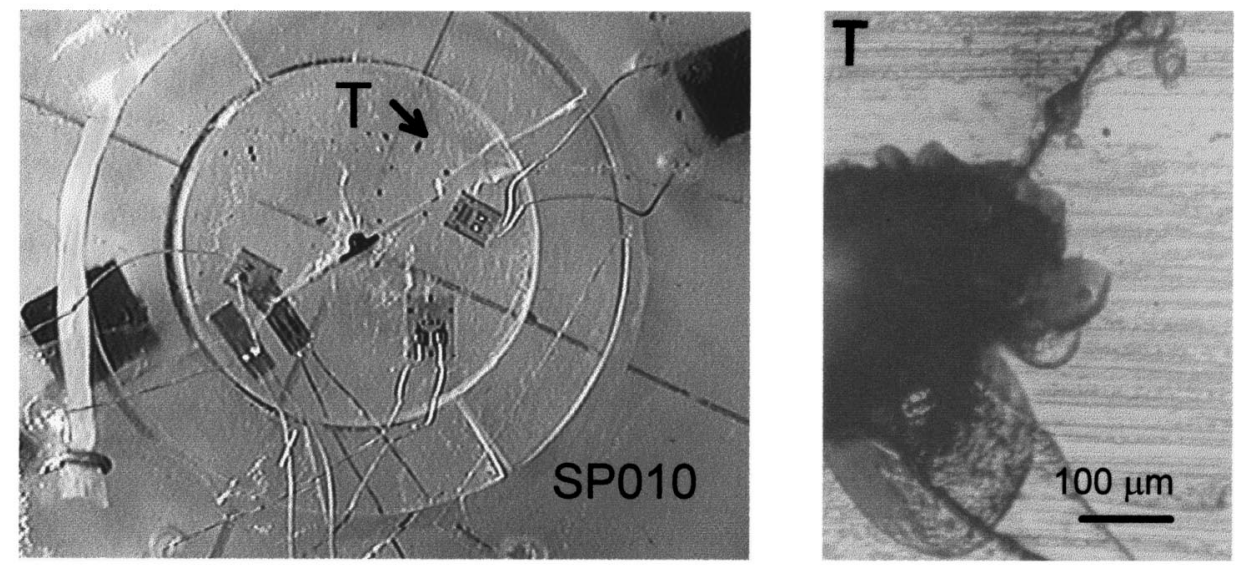

\section{Crack Tip Bifurcation}

FIG. 9. An example of fracture specimen with buffers as momentum traps. The precrack tip is indicated by $T$. The bifurcation was detailed illustrated on the right picture. 


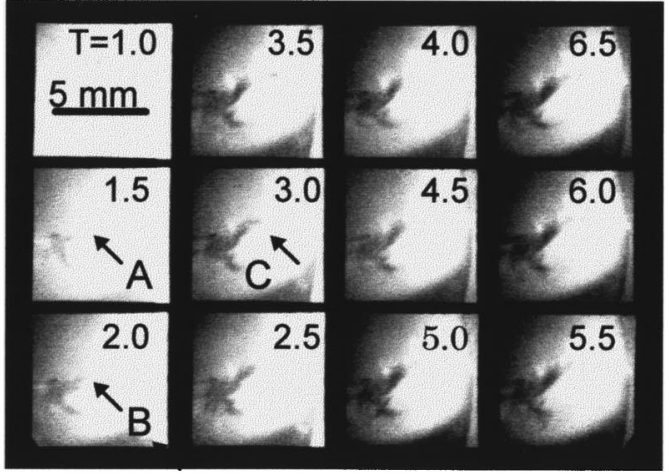

(a)

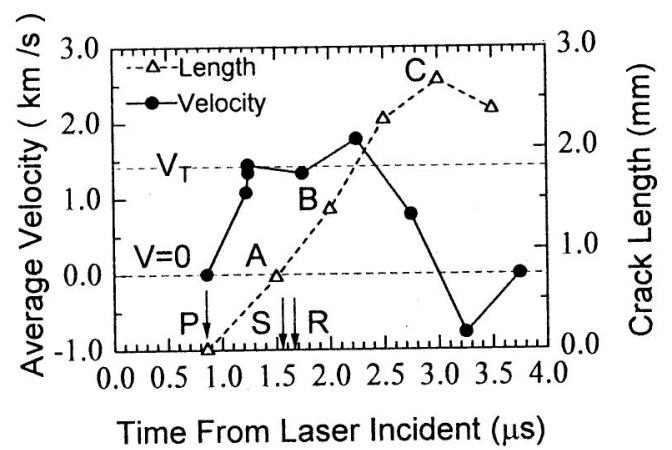

(b)

FIG. 10. Crack initiation under laser loading of Group B21. (a) High speed framing camera's record. The branching of the crack tip happened at the beginning. The crack recovered as $3 \mu$ s as the loading pulse was passed, then stayed still until the end of record. (b) Crack velocity profiles. The arrows with $P, S$, and $R$ refer to the timing that $P, S$, and $R$ waves arrived to the crack tip, respectively. The crack recovery appeared as negative velocity. The horizontal line indicates the reported terminal velocity of $1.46 \mathrm{~km} / \mathrm{s}$.

$$
Y=\frac{1-2 \nu}{1-\nu} \sigma_{\mathrm{HEL}}=2.0 \mathrm{GPa},
$$

where $\nu$ is Poisson's ratio. The phenomena constitutive behavior is similar to an elastic-plastic material in the range around $Y$. The shear strength of $Y=2.0 \mathrm{GPa}$ is also reasonable compared to the directly experimental measurement conducted by Kanel et al. ${ }^{33}$

Before the discussion of transition from voids to microcracks, let us consider the possibility of void expansion in the soda-lime glass. Currant et al. used the following equation to describe a void growth for ductile material under spherical loading: ${ }^{8}$

$$
\dot{C}+\frac{3}{2 C}(\dot{C})^{2}+\frac{4 \eta}{\rho C^{2}} \dot{C}+\frac{2 Y}{\rho C^{2}}=\frac{T-P_{c}}{\rho C} .
$$

Here $\rho, C, \eta, P_{c}$, and $T$ are the density, void size, viscosity, critical loading and the external stress, respectively. The dots indicate time derivatives. The spherical void will yield first from the inner surface where the stress concentration has occurred. The external stress level at this point is the critical loading $P_{c}$. An expression for $P_{c}$ under bulk stress is

$$
P_{c}=\frac{2}{3} Y\left(1-V_{\nu}\right),
$$

where $V_{\nu}$ is the volume proportion taken by the void. The order of void growth velocity in Eq. (1) can be estimated with the following simple expression:

$$
\frac{C}{C}=\frac{T-P_{c}}{4 \eta} .
$$

We use Table IV to compare the soda-lime glass with alu-

TABLE IV. Compare of aluminum and soda-lime glass.

\begin{tabular}{lcccc}
\hline \hline & & & $\mathrm{Al}^{\mathrm{a}}$ & Glass $^{\mathrm{b}}$ \\
\hline density & $\rho$ & $\mathrm{g} / \mathrm{cc}$ & 2.7 & 2.5 \\
viscosity & $\eta$ & poise & 200 & $\sim 10^{20}$ \\
yield stress & $\Upsilon$ & $\mathrm{GPa}$ & 0.3 & 3.6 \\
\hline \hline
\end{tabular}

${ }^{\mathrm{a}}$ Data from Ref. 8.

${ }^{\mathrm{b}}$ Data from Ref. 27. minum as an example. The viscosity of glass is about $10^{18}$ times that of aluminum, and $P_{c}$ is ten time higher. We can see that the void growth velocity, if not zero, is on the order of several tens lower than in aluminum. Although there are no simple plastic void growth expressions available for general loading, the growth velocity should not have a difference in order as in the case of hydro pressure. We can conclude that it is practically impossible for the voids in glass to change their size.

The stress concentration caused by the voids determines that the voids are the locations where cracks will be initiated. By analyzing the hoop stress in a two dimensional void, it was shown that crack initiation is possible even when the void was subjected to two dimensional compression because the MHS was still under tension. ${ }^{34}$ The necessary stress condition for the initiation is independent of the void size, and it is only sensitive to the void shape. For an elliptical void, the stress condition can be expressed by Griffith's law. ${ }^{35,36}$ Grif-

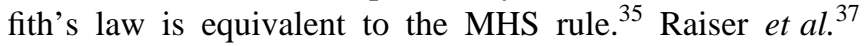
argued that the failure wave cannot be fully understood because a material under plane shock is under threedimensional compression. If the void parameters in glass are known, the crack initiation condition under uniaxial strain compression can be quantitatively illustrated using Griffith's law. We therefore conclude that the voids are candidate sites for microcracks. Figures 6 and 8 give evidence of this realization observed in our experiments. As a conclusion, the MHS on the void surface can be used as a common rule for crack initiation under tension and compression loading.

When the microcracks are nucleated, the growth process can be analyzed using the same approach as the NAG model. We stated above that the nucleation condition is sensitive to the shape, independent of the void size. However, the growth velocity of the crack has a strong nonlinear dependence on its size. The maximum velocity has a limitation of the terminal velocity ${ }^{38}$ in practice, and the Rayleigh wave speed in theory. Presently there is no generally accepted illustration of the crack velocity limit. ${ }^{39}$ The damage velocity caused by the connection of multi-cracks can be much higher. The two concepts of damage velocity and terminal velocity have al- 
ready been distinguished by the work of Honnemann et al. ${ }^{40}$

Unlike the NAG model, which uses the averaged and continuously distributed damage variable, we suggest that the evaluation of damage in a specimen should be assessed by the "most threatening crack," or the largest connected crack cluster. The final macro fracture is caused by cluster percolation. The performance of the percolation cluster according to the scaling law is suggested as the sign near failure. In brief, the three stages of the NGP can be used to study the failure process in a brittle material. It is a typical deformation-diffusion process.

\section{SIMULATION OF LASER INDUCED SPALLATION IN GLASS}

In this section, we will apply the NGP model to the analysis of spallation experiments, and describe the crack initiation experiments in the next section. The simulation is conducted through several loops, including: the simulation of shock wave propagation, the construction of the microcrack field, and the percolation statistics. The shock simulation used uniaxial strain or cylindrical plane condition to limit the calculation in one dimension. The microcrack field was constructed to plane space in the sense that the stress and strain were the same along lateral (or hoop) direction. The stress here had the meaning of infinite stress for the cracks inside a cell. The interaction between microcrack field and the stress field was established through energy conservation principle in three-dimensional space. This approach avoided the complicated analysis of microcrack singularity, and completed percolation statistics in a reasonable calculation time. However, the accuracy of the results was limited.

\section{A. Constitutive equation and stress wave propagation}

The Hugoniot data for soda-lime glass ${ }^{15,16}$ was used to construct the constitutive relationship. The permanent densification model is adopted to deal with distortion deformation with a flow strength $Y=2.0 \mathrm{GPa}$. Thus the constitutive equation has the same mathematical form as the Gruneisen equation of state (EOS) plus the ideal plastic assumption, ${ }^{4}$ i.e., the bulk stress $P$ is a function of volume strain $\epsilon$ through the Gruneisen EOS, deviatric stresses are the functions of deviatric strains following Hook's law in the elastic zone, and then of the ideal plastic model beyond the elastic zone. The constitutive curves of loading, unloading, and tension were plotted against experimental data in Fig. 11. The constitutive relationship under uniaxial and cylindrical constraints can be deduced from Fig. 11.

The finite difference method is used for the stress wave calculation. For the case of cylindrical simulation, the motion equation is

$$
V_{0}\left(\frac{\partial \sigma_{r}}{\partial r}+\frac{\sigma_{r}-\sigma_{\theta}}{r}\right)=\frac{\partial^{2} u_{r}}{\partial t^{2}} \quad(\text { compression positive }),
$$

where $V_{0}$ represents the initial specific volume, and $\sigma$ and $u$ are the stress and displacement, respectively. Subscripts $r, \theta$, and $t$ indicate spaces and time components, respectively. The

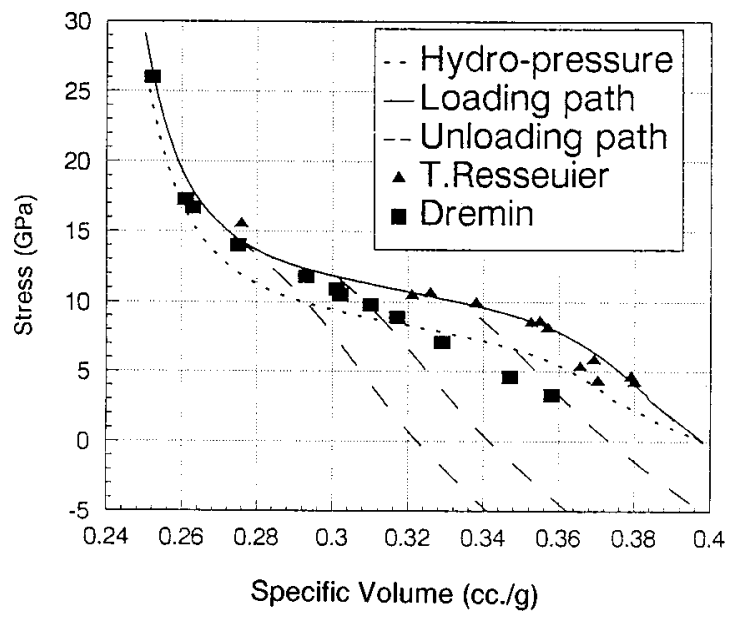

FIG. 11. Constitutive relationship of soda-lime glass. The hydro-pressure, shear strength, and unloading curves are constructed simultaneously.

continuity equation in this case can be automatically satisfied when the cross deviation for strain and velocity are made equal.

The symmetrical condition in our experiments leads to $u_{\theta}=0$, hence

$$
\epsilon_{r}=\frac{\partial u_{r}}{\partial r} \quad \epsilon_{\theta}=\frac{u_{r}}{r} \quad \epsilon_{z}=0 \quad \text { (plane strain), }
$$

therefore the expression for $\sigma_{r}$ and $\sigma_{\theta}$ beyond the elastic zone can be written as

$$
\sigma_{r}=P+\frac{1}{2 G} \frac{\left(2 \epsilon_{r}-\epsilon_{\theta}\right)}{3} \quad \sigma_{\theta}=P+\frac{1}{2 G} \frac{\left(2 \epsilon_{\theta}-\epsilon_{r}\right)}{3} .
$$

and

$$
2 \tau_{\max }=Y .
$$

Here $G$ and $\tau_{\max }$ are the shear modulus and the maximum shear stress, respectively. The results of our calculations are shown in Fig. 5. Under the loading condition noted in the figure, the plane strain condition was valid for the $2 \mathrm{~mm}$ thick cylindrical disks.

\section{B. Microcrack field}

A one-dimensional (1D) segment of a difference cell represents a $3 \mathrm{D}$ volume cell of a disk with a thickness of $\Delta x$ (or $\Delta r$ ) in uniaxial strain, and a cylinder cell with a fanshaped section. Our percolation statistics is carried on the 2D section space. A microcrack is represented as a "stick," and has four degrees of freedom of its center position $\left(x_{c}, y_{c}\right)$, its length $C$ and its orientation angle to $x$ axial $\varphi$. The stick's length represents the diameter of the penny shaped crack. We assume that the microcracks can only be nucleated under tensile stress. The nucleation rate $N$ of a specific area can be expressed by a simple model as ${ }^{8}$

$$
\frac{d N(t)}{d t}=N(t)=N_{0} \exp \left(\frac{\sigma-\sigma_{c}}{\sigma_{2}}\right) \text { for } \sigma>\sigma_{c},
$$


where $N_{0}, \sigma_{c}$, and $\sigma_{2}$ are constants. The nucleated microcracks $(\Delta N)$ are put into each cell with random location $\left(x_{c}, y_{c}\right)$, length $C$, and orientation $\varphi$. Here $C$ is limited in a meso scale as Fig. 3 showed.

We use the Mott model ${ }^{42}$ to describe the crack growth in the stress fields as

$$
C=\frac{d C}{d t}=V_{R}\left(1-\frac{C^{*}}{C}\right)^{1 / 2} \quad \text { for } C>C^{*}
$$

and

$$
C^{*}=\frac{1}{2 \pi}\left(\frac{K_{1 c}}{S_{n}}\right)^{2},
$$

where $S_{n}$ is the driver force. The driving force can be the maximum principle stress or, as in our present program, the traction perpendicular to the crack plane. Here $V_{R}$ is the maximum crack velocity. In the calculation, we usually took $V_{R}=V_{R M}=0.9 C_{R}$.

The microcrack connections are monitored in every time step. Each nucleated microcrack is organized according to the location of its center points $\left(x_{c}, y_{c}\right)$, and represented by an integer coordinates $(m, n)$, the arrangement of $m(n)$ is in the same order as the $x_{c}\left(y_{c}\right)$ value so that the neighbor microcracks have the maximum possibility of being arranged with closing $m$ and $n$ coordinates. The crack connection of one crack to all others is practically only needed to be judged among its neighbors. We find that a scan to the 5th neighbor is good enough to include all the connection possibilities with an endurable calculation time. When two crack lines cross each other, they are regarded as joined. The connected cracks are called crack clusters. A cluster is identified by a cluster number, and its length is calculated as the total crack length it included, and its size is assigned as its maximum span in lateral direction. If two clusters have a cross point, they are combined to be one cluster, and share the cluster number of the previously smaller one. Newly created microcracks are adopted with the same algorithms.

The cluster statistics are not limited by the difference cells. The clusters have no limit to their growth velocity in the sense that many cracks may be connected simultaneously.

\section{Energy equilibrium and stress relaxation in microcrack field}

It is the interaction between the stress field and the microcrack field that plays the key role in the brittle fracture mechanics. One reliable way of counting the effects of microcracks on the stress field is through the energy balance principle. Suppose our percolation analysis is carried out to a volume cell with a lateral size of $Y_{l}$, the number of cracks in the $m$ th cell is $N_{m}$, the average size is $r_{m}$, the average distance between the cracks in a cell is $R_{m}=Y_{l} / N_{m}$, then the number of total cracks in the $3 \mathrm{D}$ cell is

$$
N_{m}^{3 \mathrm{D}}=\frac{Y_{l}^{2}}{R_{m}^{2}}=N_{m}^{2} .
$$

Then the total area of cracks is

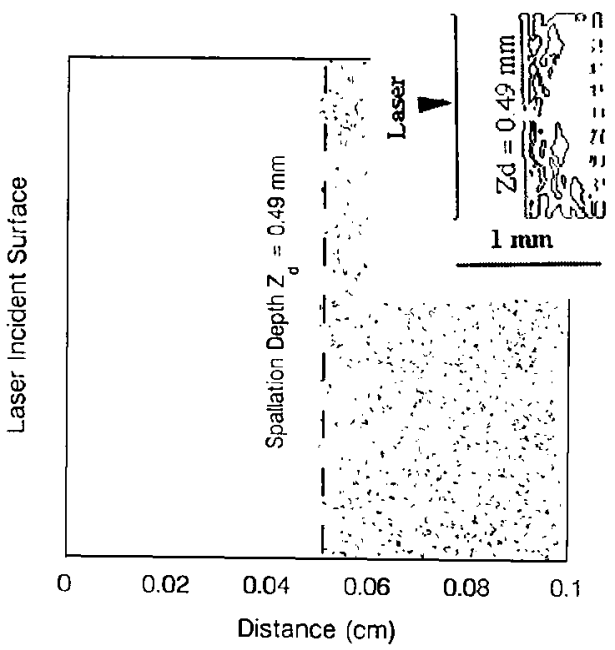

(a)

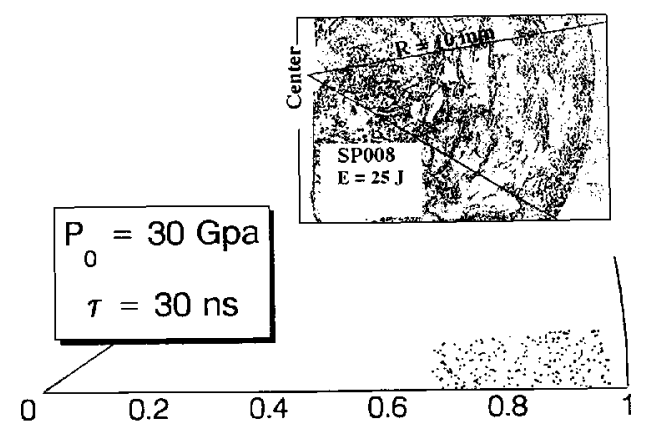

(b)

FIG. 12. Calculated crack clusters compared with those experiments: (a) uniaxial strain case, upright attached is a cluster topology of a specimen appeared as Fig. 3 in Ref. 3; (b) plane strain cylindrical case calculated to $2.4 \mu \mathrm{s}$, upright attached is a cluster diagram from our experiments. It is the topology of section B in Fig. 7.

$$
A_{c}=N_{m}^{3 \mathrm{D}} \times\left(\frac{1}{4} \pi r_{m}^{2}\right) .
$$

The energy release rate $J$ represents the surface energy taken by newly produced crack surfaces. $J$ is related to the fracture toughness in Eq. (7) through the relationship

$$
J=\frac{\left(1-\nu^{2}\right)}{E} K_{1 c}^{2} .
$$

Here $E$ is Young's modulus. The total surface energy in the mesh can be evaluated using the crack surfaces as

$$
E_{m}=2 A_{c} J \text {. }
$$

The change with respect to the precious time step of this energy, $\Delta E_{m}$, should correspond to the stress relaxation caused by crack growths. The dilatation change of specific volume in the cell is

$$
d V=2 \Delta E_{m} V / P V_{m},
$$

where $V_{m}=Y_{1}^{2} d x$ is the volume of the cell. The specific volume iteration is carried out as

$$
V^{*}=V+d V
$$

The new pressure is calculated by substituting the modified volume $V^{*}$ with the Gruneisen equation. The crack interac- 


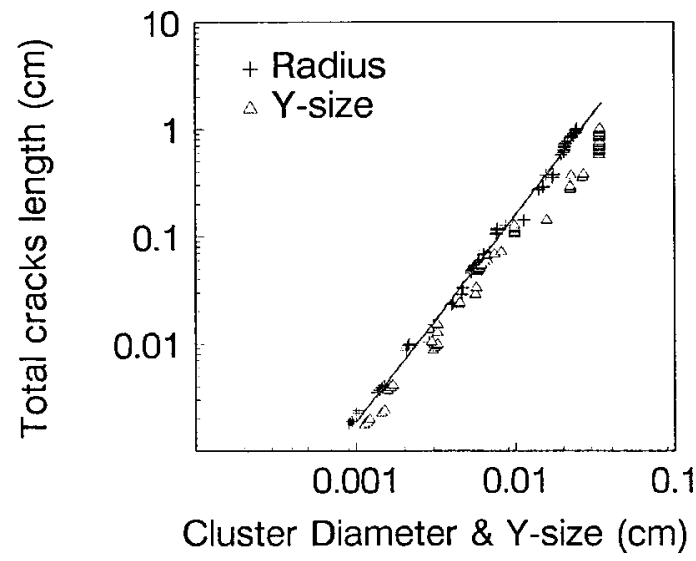

FIG. 13. Logarithmic plot of percolation clusters at different times. The percolation cluster was the largest cluster at the time step. The cluster radius was taken as the equivalent rectangular side length. The $Y$ size was the cluster span in the lateral direction.

tions between each other are not included in the above algorithm. So this is an approximation under low crack density.

The stress profiles without relaxation by microcracks are shown by the dotted lines in Fig. 5(a). The quantity of stress change is controlled by the fracture toughness and the number of microcrack.

\section{Fractal structure of the percolation cluster}

If we measure the damage zone depth $Z_{d}$ in Resseguir's experiment as the distance between the original rear surface and the observed crack nearest to the front surface after laser irradiation, this quantity is similar to the slab thickness in the spallation test of metal. The damage zone depth of Resseguier et $\mathrm{al}^{3}{ }^{3}$ was easily reproduced when we set the intact stress $\sigma_{c}$ in Eq. (7) as $0.8 \mathrm{GPa}$. These results are given in Fig. 12(a). We found that there were two possible ways to obtain the same damage zone depth. One could assume a high microcrack density and a small individual microcrack size; alternatively, there could be a low microcrack density with a relatively large crack size. To eliminate the arbitrariness of the constants in Eq. (7), we need to define the detailed structure of the damage field.

The demand to define damage field in detail is more urgent for cylindrical specimens. The damage zone depth is difficult to define in the cylindrical test since the damage had extended to the center. The ratio of $r_{m} / R_{m}$ along the axial direction is one representing the parameter. The simulated microcrack field to $2.4 \mu \mathrm{s}$ in the cylindrical spall specimen is shown in Fig. 12(b), the $r_{m} / R_{m}$ ratio in the experiments of the same location are 2-4 times larger than their simulated values. $^{41}$

The percolation method is expected to describe quantitatively the microcrack field at the stage near the final fracture. The largest cluster in the system, called the percolation cluster, was selected as the object of study because it was found that the percolation cluster has a fractal structure at the stage near the critical percolation point. Because the scaling law is the essential character of fractal, if the scaling law is observed, it indicates that percolation is about to occur. Remember that the percolation means the macro fracture, so the appearance of scaling law means that the dangerous damage state is achieved. Although the stress history of each cell may be different, the appearance of the scaling law is in general a distinguishable behavior.

Figure 13 gives a logarithmic plot of the diameter and the total length of the cracks in the percolation cluster. The data points were plotted for every time step which was on the order of one tenth of a nanosecond. It can be seen that the cluster size could be catastrophically expanded by 2 orders in several nanoseconds. Furthermore, a linear relationship with a slope of 1.93 was suggested. This is called the Fisher exponent and is the dimensional number. Since a dimensional number of 2 means the complete 2D space, the Fisher exponent in the simulation is too large as the largest crack cluster has not filled the whole specimen.

As we mentioned above, although the crack velocity limit used in the simulation is very high, the crack field produced by simulation is still of high microcrack density and small individual microcrack size, although we have used a very high $V_{R M}$ value. In contrast, the experiment is the type of low microcrack density with relatively large crack size. This indicates that the microcracks in the practice connected more efficiently than in the simulation. The microcrack field has stronger self-organization character than our simulation. Since we cannot consider the crack interactions between the cracks in the present algorithms, the detailed characteristics are not well simulated.

It must be emphasized that the fracture surface dimension is not the same as the cluster dimension obtained here. The fracture trace is the final "go through path" in the percolation cluster. It is a subspace of the cluster space. The full set of the space characters is more than can be expressed by its subspaces.

\section{NGP MODEL APPLIED TO A MAIN CRACK TIP}

In this section, we consider the NGP model simulation when a main crack exists. We tried to understand why the void activities could not be observed in the low loading rate experiments of Group A. For this purpose, we designed a simple numerical approach to examine the process. Our simulation images a crack tip in a semi-infinite space. The stress field in the vicinity of the crack tip can be expressed by the well-known singularity formulas. For mode I loading, they are:

$$
\sigma_{i j}=\frac{K_{1}}{\sqrt{2 \pi r}} f_{i j}(\theta),
$$

where $K_{1}, r$, and $f_{i j}(\theta)$ are SIF, the distance from the crack tip, and the function of angle $\theta$, respectively. The two numerical parameters $K_{1 c}$ and $V_{R M}$ were assumed to represent the fracture toughness and the crack velocity limit, respectively. We started the simulation by assuming an SIF increase rate $\dot{K}$. The main crack tip remained still before SIF $K$ overtook fracture toughness $K_{1 c}$, and moved with a speed $V_{R M}$ afterward, i.e.,

$$
K_{1}^{j}=j \dot{K} \delta t
$$




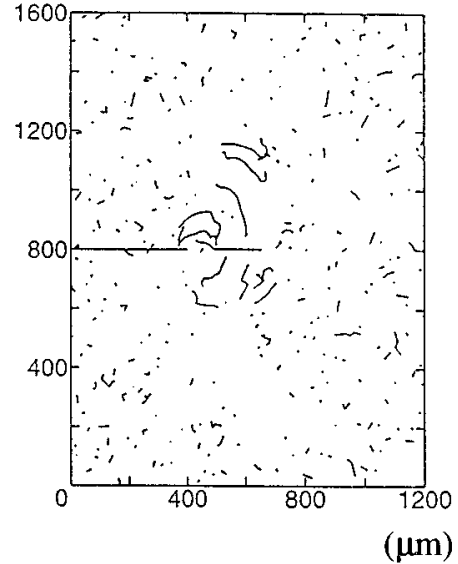

$\mathrm{t}=13(\mu \mathrm{s})$

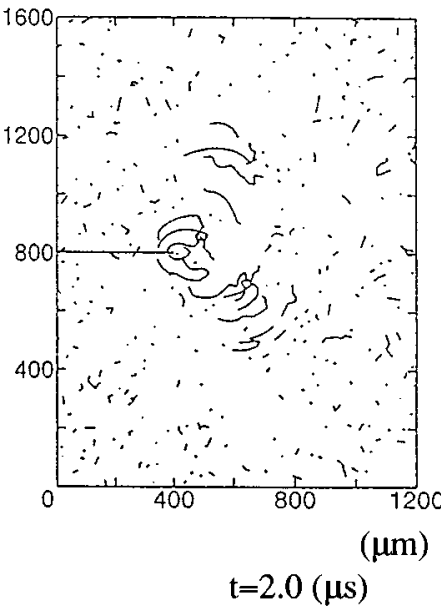

(b)

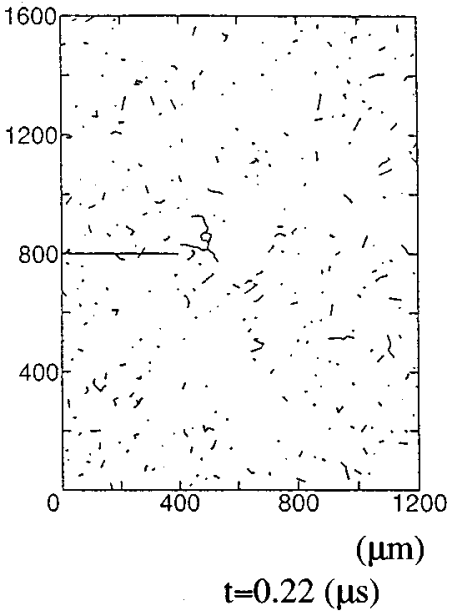

(c)

FIG. 14. Simulations of microcrack clusters in different loading rates: (a) $\dot{K}=10^{5} \mathrm{MPa} \mathrm{m}^{1 / 2} / \mathrm{s}$, (b) $\dot{K}=10^{6} \mathrm{MPa} \mathrm{m}^{1 / 2} / \mathrm{s}$, (c) $\dot{K}=10^{7} \mathrm{MPa} \mathrm{m} \mathrm{m}^{1 / 2} / \mathrm{s}$.

$$
\begin{aligned}
& V_{\text {main }}=0 \quad \text { when } K_{1}^{j}<K_{1 c}, \\
& V_{\text {main }}=V_{R M} \text { when } K_{1}^{j}>K_{1 c},
\end{aligned}
$$

where $j, \delta t$, and $V_{\text {main }}$ are the step number, time step, and main crack velocity, respectively. Equations (7)-(9) are used again for penny shaped microcracks. The microcracks were then nucleated, grown, and connected according to the NGP model. This is the same as in Sec. IV. This time, the interactions between the main crack and the microcracks, as well as the interactions between the microcracks were considered by using the results of Gong et al. ${ }^{43}$ The organization of the clusters was also improved by considering only pure connection, i.e., crack tips were stopped when they reached crossing points. By these improvements, the effects of microcracks on the main crack could be examined.

We found that the patterns were quite different under high and low loading rates. Figures 14 and 15 give typical examples of the simulations.
The microcrack fields at the same SIF $K_{1}$ were plotted for three loading rates as shown in Fig. 14. Under the high loading rate, there are many small cracks connected to form the clusters. The cluster sizes were always much larger than any single crack. There was sometimes severe damage before the main crack initiation when we increased the nucleation site density. While in the low loading rate, it appeared that only one or two cracks grew, and the number of clusters was less than the high loading rate. Most microcracks stayed at nearly the same sizes as when they were nucleated. Before the damage zone was formed, the main crack had gone out of the "process zone." These patterns did not change with the material parameters used in the simulation. We regard these pattern changes under different loading rates to be a general rule.

The SIF profiles of the main crack tip affected by the microcracks are shown in Fig. 15. The microcrack nucleation indicated a severe effect on the main crack at the low loading

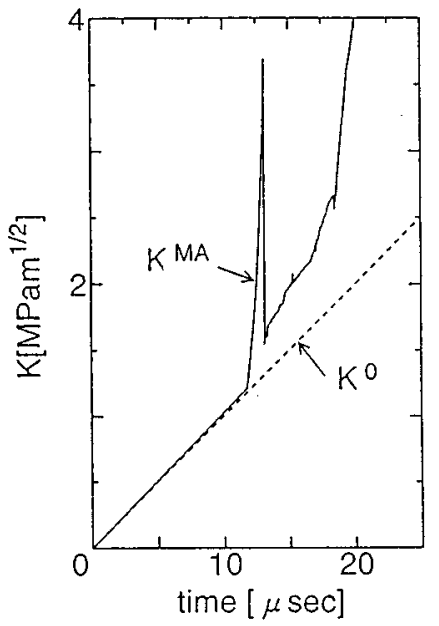

(a)

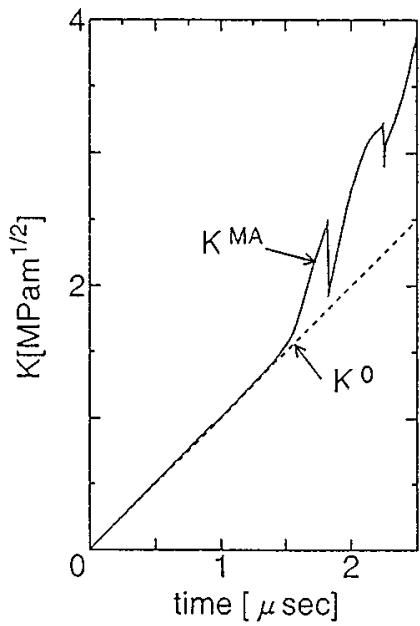

(b)

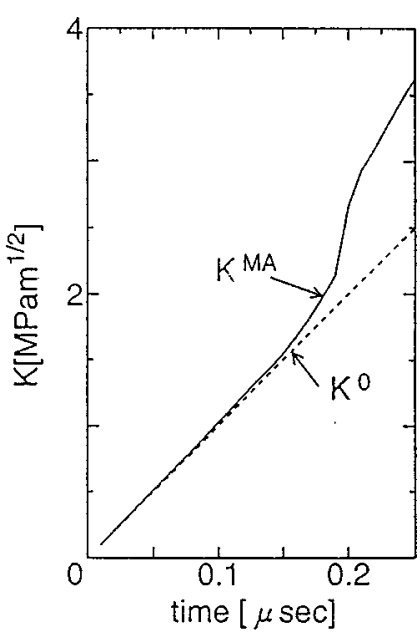

(c)

FIG. 15. The SIF profiles of the main crack tip. The original profiles are straight lines indicated by dashed lines $K^{0}$. The presence of microcracks increase the danger of instability for the main crack indicated by superscript ${ }^{\mathrm{MA}}$. Note the different characters governed by the loading rates: (a) $\dot{K}=10^{5} \mathrm{MPa} \mathrm{m}^{1 / 2} / \mathrm{s}$, (b) $\dot{K}=10^{6} \mathrm{MPa} \mathrm{m}{ }^{1 / 2} / \mathrm{s}$, (c) $\dot{K}=10^{7} \mathrm{MPa} \mathrm{m}{ }^{1 / 2} / \mathrm{s}$. 
rate. The nucleation caused instability of the main crack, while at this time, the microcrack field had not yet been fully developed. The process zone is small. One can imagine that if a main crack was propagated, it would be difficult to observe the microcrack traces on the fracture surface such as in the cases of Figs. 1(a) and 2(a). On the other hand, at high loading rate, the main crack's SIF showed a ramp increase due to microcrack growth as shown in Fig. 15(c). In a fully developed microcrack field, the main crack would propagate through a large process zone with a lot of microcracks, or the percolation of microcracks would make a main crack appear in the propagation phase. The stress or damage localization became weaker as the loading rate increased.

There is already much experimental evidence supporting the above conclusions. ${ }^{44-46}$ As can be seen from our simulations it is the strong nonlinear interaction between microcracks, and the strong nonlinear dependence of velocity to length that caused such behavior.

Although one may question the validity of the Mott model, we feel that the nonlinear feedback behavior is a general characteristic of all other crack growth models. ${ }^{47}$ The essential phenomena will be the same.

The incubated bifurcation directions can also be checked in Fig. 12. The bifurcation angle of $104^{\circ}$ is in a reasonable range compared with the simulations.

\section{DISCUSSION}

There is an opinion that the percolation theory is unable to describe the failure process because failure may not be a critical phenomenon. ${ }^{25}$ The critical characteristics of percolation can be understood from the fundamental features of a randomly distributed field, e.g., if the number of neighbors for a member is known to follow the Poisson distribution, the percolation scaling relationship is valid. ${ }^{48}$ The probability for a member to have $k$ neighbors in the Poisson distribution is:

$$
p_{k}=\frac{B^{k}}{k !} \exp (-B) \text {. }
$$

Here $B$ is the average neighbor number. The microcracks are the members in our case, the Poisson distribution can be broken due to microcrack growth, and the scaling law based on the distribution function is also violated.

We suggest to introduce a quantity as

$$
\Psi=\frac{D_{g}}{D_{n}},
$$

here

$$
\begin{aligned}
D_{g}= & \text { damage rate contributed by growth of damage } \\
& \text { members, } \\
D_{n}= & \text { damage rate contributed by nucleation of } \\
& \text { new members, }
\end{aligned}
$$

so that $\Psi$ represents the ratio of the growth rate to that of nucleation. If we use $N(t)$ to represent the total number of microcracks as in Sec. IV, we can write

$$
\begin{aligned}
& D_{g}=N(t) \frac{d \bar{C}}{d t}=N(t) \dot{\bar{C}} \\
& D_{n}=\frac{d N}{d t} \overline{C_{0}}=\dot{N} \overline{C_{0}} .
\end{aligned}
$$

Here $C$ represents the microcrack length as before, the bar over $C$ represents its average, and subscript ${ }_{0}$ represents its initial value when nucleated. Since $\overline{C_{0}}$ is only decided by the initial defect distribution, it does not change with time for a specific material. Thus we can write

$$
\Psi=\frac{\bar{C}}{\overline{C_{0}}} \frac{\frac{d \bar{C}}{\frac{\bar{C}}{N}}}{\frac{d N}{N}}=\frac{\bar{C}}{\overline{C_{0}}} \frac{d(\ln \bar{C})}{d(\ln N)} .
$$

We can see here that the denominator represents the defect character of the material and their changes when subjected to stress or other factors, while the numerator represents the response of the crack-a kind of mechanical structure-to external forces. So $\Psi$ is a parameter representing the comprehensive material characteristics of strength. It is clear that this is a physics variable, while the failure pattern and other details are the mathematical results from specific load conditions.

It is a pity that we had not output $\Psi$ in the simulations this time. We can only clarify the situations for two specific values of $\Psi$. One is the case when $\Psi=0$, i.e., $d C=0$, which means all the defects can be excited but cannot be amplified. This is the standard percolation. The other case is when $\Psi$ $=\infty$, i.e., $d N=0$, which means that the growth is the dominant factor and there is no microcrack nucleation. Generally, it is possible for $\Psi$ to have a value from 0 to $\infty$, so the failure pattern is also changed from percolation to crack extension. We think this is why the failure phenomenon can be such a complex problem. However, if we take the maximum crack cluster as the representative variable despite the different stress history between locations, we can achieve reliability in engineering and uniqueness in theory. We therefore suggest that the NGP concept is valid.

The stress field in the intact media should be efficiently adjusted according to the microcrack field in every time step. This is still difficult now and limits the precision of our calculations. One numerical method which might deal with this problem may be the particle dynamic method, ${ }^{22}$ although we have not obtained valuable results yet.

\section{CONCLUSION}

The microcracks in the brittle material before a fatal fracture especially under ultrahigh loading rates have been studied in this article. The microcracks, as an important kind of damage, are related to the loading rates effect and the deformation localization. Such researches have a history of more than ten years, but understanding is still limited to the empirical level. To achieve a breakthrough, fresh approaches in both experiment and theory are needed. We have devel- 
oped an experimental method using pulsed laser loading, and used percolation theory to explore the transition from random damage to deterministic failure.

In the laser loading experiments, we observed branching at the initiation of crack extension. The crack velocity was observed to obey the terminal velocity rule quantitatively. Observations after the experiments showed much evidence of microcrack activity. The experiments proved that the laser had the ability to conduct crack opening experiments and at a very high loading. The laser loading method also showed the special ability to reveal the micro mechanism.

We interpreted our meso mechanics methodology by the NGP model. Basically, the intact material means that of the material that contains unactivated or submeso scale defects, the stresses are only defined in this region. The crack cluster geometry is observed directly to evaluate the danger of failure. The NGP model was applied to the simulations of laser induced spallation experiments and the evolution of microcrack fields in front of the main crack tip. These simulations provided answers to many questions that were not clear before. Our new laser method and NGP model were successfully able to explain, among others, why the microcrack activities could not be observed in quasi-static fracture experiments, and why branching initiation occurred in the laser loading experiments. This research is still in the primary stage and if developed could obtain more quantitative results.

\section{ACKNOWLEDGMENTS}

The authors would like to express their thanks to Professor M. Boustie and Dr. H. Yoneda for providing research data. K. Watanabe, S. Fujiwara, H. Hara, Dr. H. Shiraga, and other members in the MII group at ILE are sincerely acknowledged for their technical assistance. The authors would also like to thank M. Miyazaki of Mitsubishi Electric Co. for his continued support.

${ }^{1}$ F. R. Tuler and B. M. Butcher, Int. J. Fract. Mech. 4, 431 (1968).

${ }^{2}$ G. I. Kanel and A. V. Utkin, in Shock Compression of Condensed Matter1995, edited by S. C. Schmidt and W. C. Tao (Springer, New York, 1996), p. 487.

${ }^{3}$ T. de Ressegiur and F. Cottet, J. Appl. Phys. 77, 3756 (1995).

${ }^{4}$ K. Takahashi and K. Arakawa, Exp. Mech. 27, 195 (1987).

${ }^{5}$ M. Nakano, K. Kishida, and K. Yoshimoto, Mechanical Behavior of Materials-VI, edited by M. Jona and T. Inoue (Pergamon, New York, 1991), p. 419.

${ }^{6}$ K. Ravi-Chander and W. G. Knauss, Int. J. Fract. 25, 247 (1984).

${ }^{7}$ D. A. Shockey, D. C. Erlich, J. F. Kaltoff, and H. Homma, Eng. Fract. Mech. 23, 311 (1986)

${ }^{8}$ D. R. Curran, L. Seaman, and D. A. Shockey, Phys. Rep. 147, 253 (1987).

${ }^{9}$ C. W. Sun, S. M. Zhuang, Y. P. Wang, and C. L. Liu, in High-Pressure Shock Compression of Solids II, edited by L. Davison, D. E. Grady, and M. Shahinpoor (Springer, New York, 1996), Ch. 3, pp. 71-87.

${ }^{10}$ M. Watababe, J. Appl. Mech. 61, 210 (1994).
${ }^{11}$ J. A. Fox and D. N. Barr, Appl. Phys. Lett. 22, 594 (1973).

${ }^{12}$ K. A. Tanaka, Y. Kato, S. Nakai, H. Shiraga, T. Yabe, T. Yamanaka, T. Endo, R. Kodama, and C. Yamanaka, Laser Part. Beams 7, 495 (1989).

${ }^{13}$ A. M. Evans, N. J. Freeman, P. Graham, C. J. Horsfield, S. D. Rothman, B. R. Thomas, and A. J. Tyrrell, Laser Part. Beams 14, 113 (1996).

${ }^{14}$ Y. Gu, S. Z. Fu, J. Wu, A. Y. Yu, Y. L. Ni, and S. J. Wang, Laser Part. Beams 14, 157 (1996).

${ }^{15}$ T. de Resseguier, F. Cottet, and A. Migault, J. DYMAT 1, 31 (1994).

${ }^{16}$ A. N. Dremin and C. A. Adadurov, Sov. Phys. Solid State 6, 1379 (1964).

${ }^{17}$ N. S. Brar, S. J. Bless, and Z. Rosenberg, Appl. Phys. Lett. 59, 3396 (1991).

${ }^{18}$ N. K. Bourne, Z. Rosenberg, and J. E. Field, J. Appl. Phys. 78, 3736 (1995).

${ }^{19}$ G. I. Kanel, S. V. Razorenov, and A. V. Utkin, in High-Pressure Shock Compression of Solids II, edited by L. Davison, D. E. Grady, and M. Shahinpoor (Springer, New York, 1996), Ch. 1, pp. 1-22.

${ }^{20}$ D. Singh and D. K. Shetty, J. Am. Ceram. Soc. 73, 3597 (1990).

${ }^{21}$ M. Nakano, K. Kishida, Y. Yamauchi, and Y. Sogabe, J. Phys. IV 4, 695 (1994).

${ }^{22}$ X. Z. Li, Doctoral thesis, Osaka University, 1996.

${ }^{23}$ G. Grimmett, Percolation (Springer, New York, 1989), p. 3.

${ }^{24}$ P. M. Duxbuxy, P. L. Leath, and P. D. Beale, Phys. Rev. B 36, 367 (1987).

${ }^{25}$ M. F. Xia, W. S. Han, F. J. Ke, and Y. L. Bai, Chin. Adv. Mech. 25(I), 1 (1994); 25(II), 145 (1994).

${ }^{26}$ D. L. Tonks, J. Phys. IV 4, 665 (1994)

${ }^{27}$ T. Moritani, S. Naruse, M. Kunugi, and H. Tashiro, Glass Engineering Handbook (Asakura Shoten, Tokyo, 1970), Ch. 9, p. 409.

${ }^{28}$ C. R. Phipps, Jr., T. P. Turner, R. F. Harrison, G. W. York, Z. Osborne, G. K. Andson, X. F. Corlis, L. C. Haynes, H. S. Steele, K. C. Spicochi, and T. R. King, J. Appl. Phys. 64, 1083 (1988).

${ }^{29}$ K. Ravi-Chander and W. G. Knauss, Int. J. Fract. 26, 141 (1984).

${ }^{30}$ X. Z. Li, M. Nakano, Y. Yamauchi, K. Kishida, and T. A. Tanaka, "Fracture process of glass revealed in laser shock wave experiments," Proceedings of 2nd International Symposium on Impact Engineering, edited by C. Y. Chien (Chinese Journal of Mechanics Press, 1996), p. 295.

${ }^{31}$ J. K. West and L. L. J. Hench, Mater. Sci. 29, 3601 (1994).

${ }^{32}$ J. K. West and L. L. J. Hench, Mater. Sci. 29, 5898 (1994).

${ }^{33}$ G. I. Kanel, A. M. Molodets, and A. N. Dremin, Combust. Explosive Shock Waves 13, 772 (1977).

${ }^{34}$ E. G. Bombolakis, in Dynamic Crack Propagation, edited by G. C. Sih (Lehigh University Press, Bethlehem, PA, 1972), p. 103.

${ }^{35}$ J. C. Jaeger, Elasticity, Fracture and Flow (Methan \& Co. LTD, London, 1964), p. 174.

${ }^{36}$ Z. Rosenberg, J. Appl. Phys. 76, 1543 (1994).

${ }^{37}$ G. F. Raiser, J. L. Wise, R. J. Clifton, D. E. Grady, and D. E. Cox, J. Appl. Phys. 75, 3862 (1994).

${ }^{38}$ F. Kerkhof, in Dynamic Crack Propagation, edited by G. C. Sih (Lehigh University Press, Bethlehem, PA, 1972), p. 3.

${ }^{39}$ P. D. Whashobaugh and W. G. Knauss, Int. J. Fract. 65, 97 (1994).

${ }^{40}$ U. Hornemann, H. Rothenhausler, H. Senf, J. F. Kalthoff, and S. Winkler, Inst. Phys. Conf. Ser. 70, 291 (1984).

${ }^{41}$ X. Z. Li, M. Nakano, Y. Yamauchi, K. Kishida, and T. A. Tanaka, Constitutive Relation in High/Very High Loading Rates, edited by K. Kawata and J. Shiori (Springer, Tokyo, 1996), p. 493.

${ }^{42}$ N. F. Mott, Engineering Jan, 16 (1948).

${ }^{43}$ S. X. Gong and H. Horii, J. Mech. Phys. Solids 37, 37 (1989).

${ }^{44}$ K. B. Broberg, Constitutive Relation in High/Very High Strain Rates, edited by K. Kawata and J. Shioiri (Springer, Tokyo, 1996), p. 182.

${ }^{45}$ E. Johnson, Int. J. Fract. 55, 47 (1992).

${ }^{46}$ E. Johnson, Int. J. Fract. 61, 183 (1993).

${ }^{47}$ J. P. Berry, J. Mech. Phys. Solids 8, 194 (1960).

${ }^{48}$ U. Alon, I. Balberg, and A. Drory, Phys. Rev. Lett. 66, 2879 (1991). 